\title{
Comportamentos no trânsito: um estudo epidemiológico com estudantes universitários
}

\author{
Driving-related behavior: an epidemiologic \\ study of undergraduate students
}

Leticia Marín-León 1

Marília Martins Vizzotto 2

\footnotetext{
1 Departamento de Medicina Preventiva e Social, Faculdade de Ciências Médicas, Universidade Estadual de Campinas. Cidade Universitária Zeferino Vaz, C.P. 6111, Campinas, SP 13084-971, Brasil. leticia@fcm.unicamp.br

2 Faculdade de Psicologia e Fonoaudiologia, Universidade Metodista de São Paulo. Av. Dom Jaime de Barros Câmara 1000, São Bernardo do Campo, SP 09895-400, Brasil. mmvizzotto@ig.com.br
}

\begin{abstract}
The purpose of this article was to describe self-reported driving-related behavior and compare the frequency of risk-taking among drivers with and without a history of traffic accidents (TA). A cross-sectional study was designed, and 2,116 undergraduate students from a public university in Brazil ranging in age from 18 to 25 were interviewed. Association between independent variables and history of TA was described using frequency, $\chi^{2}, p$, odds ratio, and 95\% confidence intervals. Male data were analyzed through logistic regression. Men showed a higher risk than women of having been involved in TA. Drivers with more frequent risk-taking had a greater risk of history of TA. Behaviors observed to be associated with TA in men were: "history of fines", "driving on the shoulder", and "drinking and driving". Open-ended questions demonstrated that students show low awareness of their own responsibility in TA. Interventions among students are necessary and must prioritize males and mainly those from upper socioeconomic groups.
\end{abstract}

Key words Traffic Accidents; Risk Behavior; Students

Resumo Com o objetivo de descrever os comportamentos auto-referidos no trânsito e comparar a freqüência de comportamentos de risco entre condutores com e sem história de acidentes de trânsito (AT), foi realizado um estudo transversal com 2.116 estudantes de 18 a 25 anos, de uma universidade pública do Brasil. Para observar quais as variáveis independentes que se associam ao antecedente de AT como condutor de carro, foram calculadas: freqüências, $\chi^{2}$, $p$, odds ratio $e$ intervalo de confiança de 95\%. O sexo masculino foi analisado mediante modelo de Regressão Logística. Observou-se maior risco de AT no sexo masculino. Os condutores com maior freqüência de comportamentos inseguros para o trânsito apresentaram maior risco de AT. No sexo masculino as variáveis comportamentais associadas a AT foram "ter sido multado", "dirigir pelo acostamento" e "dirigir logo após consumir álcool". Também foi observado que os jovens tendem a não reconhecer sua responsabilidade nos AT. São necessárias intervenções dirigidas aos estudantes, devendo priorizar os homens, especialmente os de renda elevada.

Palavras-chave Acidentes de Trânsito; Comportamento de Risco; Estudantes 


\section{Introdução}

Os acidentes de trânsito (AT) e as variáveis que os circundam, tais como comportamento humano, tecnologia, engenharia de tráfego, entre outras, têm sido foco de preocupação social. A deficiência do sistema de transporte público e o aumento populacional, por exemplo, têm estimulado o uso do carro. A título de ilustração, no Município de Campinas, há 2,8 habitantes por veículo; cifra que indica um consumo de automóveis inferior só ao dos Estados Unidos e da França, onde este indicador é de 1,9 e 2,6 respectivamente.

Embora o Código Nacional de Trânsito, em vigor desde 1998, constitua um marco no controle dos acidentes, Taha (2001) alerta para a reversão da tendência decrescente dos AT observada no período imediatamente após sua implantação.

A elevada mortalidade por AT representa um problema de saúde pública tanto no Brasil como em diversos países (Mello-Jorge et al., 1997; Yunes \& Rajs, 1994), observando-se no Brasil 19 óbitos / 100.000 habitantes, no primeiro qüinqüênio dos anos 90. Os jovens, especialmente do sexo masculino, são o grupo com maior envolvimento em acidentes de trânsito fatais (Andrade \& Jorge, 2000; Zhang et al., 2000).

Os comportamentos no trânsito têm sido objeto de estudo, tanto no campo das ciências do comportamento humano quanto na saúde pública. No Reino Unido, analisaram-se 2.130 acidentes, sendo $93 \%$ atribuídos a fatores humanos, $28 \%$ a fatores ambientais e $8,5 \%$ a defeitos no veículo (OMS, 1976).

Parker et al. (1995) mostraram que a tendência para acidentes pode ser prognosticada a partir das infrações referidas pelo próprio motorista. Segundo West et al. (1993), a velocidade auto-referida também pode ser utilizada como bom indicador de envolvimento em acidentes.

Sobre padrões comportamentais de risco, pode-se lembrar aspectos da teoria de personalidade proposta por Zuckerman (1988). Entre os traços de personalidade descritos, estão os denominados "busca de sensações fortes" (high sensation seeking), que se caracterizam pela preferência por novidades e pelo desejo de arriscar-se para consegui-las. Esses traços de personalidade estariam associados a altos níveis de testosterona e níveis menores de monoaminooxidase (MAO) no sistema nervoso central, sugerindo assim, uma base biológica para tais comportamentos. Para Arnett et al. (1997), o descaso e a agressividade seriam características dessa personalidade que, na sua pesquisa, mostraram-se associadas à alta velocidade e ao comportamento infrator no trânsito.
No Canadá, Zhang et al. (2000) identificam que nos jovens a falta de experiência, o limitado poder de decisão, a velocidade excessiva e as infrações se associam a AT fatais. Marín \& Queiroz (2000), numa revisão de diversos fatores que contribuem para a ocorrência de AT, abordam a importância do comportamento. Como o trânsito exige decisões rápidas, torna-se necessário considerar o estilo de conduzir, o modo pelo qual as pessoas fazem julgamentos e tomam decisões; entre elas, as de ultrapassar, mudar de pista e avançar sinal. O consumo de álcool é o fator mais associado a AT, pois dificulta a tomada de decisões e entorpece as habilidades psicomotoras. Nos jovens, a tomada de decisões é marcada pela impulsividade, ousadia e confiança excessiva em sua própria destreza.

Acidentes de trânsito e as variáveis a eles associadas representam um problema social, havendo assim necessidade de ampliação de estudos, especialmente no campo comportamental e atitudinal. Com o intuito de contribuir na compreensão desta temática, o presente estudo, de natureza descritiva e exploratória, tem por objetivos descrever e comparar condutores jovens com e sem história de AT quanto a: (1) o perfil demográfico e sócio-econômico, (2) comportamentos no trânsito e (3) julgamentos e opiniões sobre o trânsito e reações emocionais quanto à velocidade e AT.

\section{Métodos}

Neste estudo se descrevem os dados referidos por 1.642 condutores, integrantes de uma amostra não aleatória de 2.116 estudantes de uma universidade pública, na cidade de Campinas, São Paulo. Os estudantes responderam a um questionário no período de matrícula do segundo semestre de 1996.

Os critérios de inclusão foram: ser aluno da graduação e ter idade entre 18 e 25 anos. No semestre do estudo, matricularam-se na graduação, 7.260 alunos, sendo 57,8\% homens e 42,2\% mulheres. Foram distribuídos 2.850 questionários e 598 não foram devolvidos, o que representa $21 \%$ de "não-resposta" (NR). Houve 139 $(4,9 \%)$ questionários excluídos por não cumprir os critérios de inclusão. Dessa forma, os 2.116 questionários representam 29,1\% dos alunos matriculados desta faixa etária, sendo 1.214 homens $(57,4 \%)$ e 902 mulheres $(42,6 \%)$. Embora seja uma amostra por conveniência, refletiu a distribuição dos sexos existente entre os alunos de graduação.

O instrumento construído pelos autores é um questionário semi-estruturado, auto-apli- 
cável, de 50 perguntas. Para descrição, agruparam-se as variáveis nos seguintes itens:

- Características demográficas gerais: idade, sexo, curso e ano de ingresso, cidade e estado de procedência e local de moradia.

- Características sócio-econômicas: renda mensal dos pais, fonte de renda do próprio estudante, montante dos gastos do estudante e número de carros da família.

- Experiência no trânsito: visa a definir tempo de exposição à direção (idade com que começou a dirigir carro, idade com que tirou carteira de motorista) e a freqüência com que essa atividade ocorre atualmente (acesso regular a carro da família, freqüência com que dirigiu carro nos últimos 6 meses e meio habitual de transporte para a universidade).

- Comportamentos no trânsito: visa a caracterizar os condutores segundo comportamentos tidos como recomendáveis para a prevenção de lesões graves (uso de cinto de segurança); comportamentos que denotam infração das normas do trânsito (multas, suborno a policiais); comportamentos que representam risco para a segurança de outros (brigas ou discussões, "rachas", velocidade média e máxima acima da permitida, ultrapassagens proibidas, passar sinal fechado, dirigir na contramão, dirigir pelo acostamento, dirigir após beber) e ceder às pressões do grupo ou sentir insegurança por causa dessas pressões quando dirige. A variável ter sido multado ou multa, embora requeira de atuação policial, tem implícito o fato de transgressão dos regulamentos do trânsito. Como as transgressões são decorrentes de comportamentos, incluímos a variável multas nesta categoria.

- Antecedentes de acidentes no trânsito: informações que visam a caracterizar o envolvimento em AT enquanto dirigia carro; esta é a variável dependente sobre a qual está centrada a análise dos dados. Integra também este item, a caracterização segundo a exposição a "acidentes enquanto acompanhante", para identificar como este evento modificou as opiniões e os comportamentos no trânsito. Definiu-se acidente como qualquer impacto do veículo no trânsito, mesmo que sem ferimento de pessoas. - Opiniões, julgamentos sobre o trânsito: pretende configurar um panorama sobre as crenças e opiniões dos jovens (soluções para melhorar o trânsito, agressividade como critério para ser bom motorista, carteira de habilitação com 16 anos, lei incisiva para infratores de trânsito, circunstâncias que contribuíram para os acidentes em que se envolveram).

- Reações emocionais e emoções: investiga sentimentos e emoções ao atingir alta velocida- de, significado de dispor de carro, repercussões pessoais de acidentes em que esteve envolvido, sentimentos suscitados pelo fato de pessoas conhecidas terem sofrido acidentes graves ou fatais.

O instrumento foi distribuído em dez dias consecutivos a todos os estudantes que se encontravam na fila única para matricula. $\mathrm{O}$ tempo médio de resposta ao questionário foi de 20 minutos. Dando cumprimento ao documento Diretrizes Éticas para Pesquisa em Sujeitos Humanos Financiadas pela Fundação de Amparo à Pesquisa do Estado de São Paulo, junto com o questionário foi entregue uma carta explicando a finalidade e o sigilo do estudo.

O processamento dos dados constou de categorização de questões abertas e digitação das respostas codificadas em banco de dados criado no programa Epi Info.

A análise dos dados inicia-se pela verificação univariada das perguntas fechadas, visando observar se o envolvimento ou não em AT como condutor de carro (variável dependente) difere segundo perfil demográfico, sócio-econômico, de exposição à direção e comportamentos no trânsito. Utilizando o Epi Info, foram calculadas: freqüências, $\mathrm{x}^{2}, \mathrm{p}$, odds ratio (OR) e seu intervalo de confiança (IC) de 95\%. De forma complementar, as categorias identificadas mediante perguntas abertas são descritas usandose freqüência e valor de p, visando ampliar a caracterização de acidentados e não acidentados. Finalmente, apenas as variáveis com diferença estatística significativa foram submetidas à análise multivariada; recorreu-se ao modelo de Regressão Logística, utilizando o programa SAS. Mediante o método de seleção Stepwise foram escolhidas as variáveis do modelo final. Embora num primeiro modelo incluíramse ambos os sexos, devido à maior freqüência de AT entre os homens, apresenta-se neste artigo apenas o modelo masculino.

\section{Resultados}

O perfil demográfico, sócio-econômico e de exposição à direção, difere segundo o envolvimento ou não em AT (Tabela 1). Destaca-se a maior freqüência de acidentes entre os homens. A maior proporção do grupo de 20 anos e mais entre os acidentados, explica-se pelo maior número de anos como motorista. Existem diferenças sócio-econômicas significativas entre condutores com historia de AT e sem esse antecedente. Os condutores com envolvimento em AT pertencem em maior proporção a famílias com renda elevada (igual ou superior 
Características demográficas, sócio-econômicas e de exposição ao trânsito entre condutores de ambos os sexos, segundo antecedentes de acidente de trânsito $(n=1.638)$. Campinas, São Paulo, Brasil, 1996.

\begin{tabular}{|c|c|c|c|c|c|c|}
\hline Variáveis & $\begin{array}{l}\text { Acidentados } \\
(\%)\end{array}$ & $\begin{array}{c}\text { Não-acidentados } \\
(\%)\end{array}$ & $x^{2}$ & $\mathbf{p}$ & OR bruto & IC $95 \%$ \\
\hline Sexo masculino & 75,1 & 55,9 & 53,59 & 0,001 & 2,38 & $1,87-3,04$ \\
\hline Idade $\geq 20$ anos & 84,9 & 69,9 & 40,01 & 0,000 & 2,42 & $1,81-3,23$ \\
\hline Renda mensal dos pais $\geq \mathrm{R} \$ 3.000,00$ & 55,4 & 40,6 & 28,47 & 0,000 & 1,82 & $1,45-2,28$ \\
\hline $\begin{array}{l}\text { Carros pertencentes à família } \\
\text { ( } 3 \text { ou mais carros) }\end{array}$ & 46,0 & 27,8 & 49,41 & 0,000 & 2,21 & $1,76-2,78$ \\
\hline Freqüência na direção = habitual & 39,3 & 17,9 & 85,8 & 0,001 & 2,96 & $2,33-3,77$ \\
\hline Acesso regular a carro da família & 90,6 & 77,2 & 40,30 & 0,001 & 2,85 & $2,02-4,04$ \\
\hline $\begin{array}{l}\text { Meio de transporte à universidade }= \\
\text { veículo próprio ou da família }\end{array}$ & 62,6 & 36,9 & 91,42 & 0,000 & 2,86 & $2,29-3,59$ \\
\hline AT enquanto acompanhante & 59,0 & 37,8 & 61,23 & 0,001 & 2,37 & $1,89-2,96$ \\
\hline
\end{tabular}

a R\$ $3.000,00$ ) e provêm, em maior proporção, de famílias que têm 3 ou mais carros.

Ainda, os acidentados têm maior acesso ao uso de carros da família e, especialmente, diferem no fato de usar carro próprio ou da família para deslocar-se à universidade. Também a freqüência com que o condutor dirige tem relação com a ocorrência de AT, pois a proporção de condutores habituais é maior entre os com antecedente de AT do que aqueles sem esse antecedente. As variáveis indicativas de exposição à direção apontam que é maior o risco de AT quando a exposição ao trânsito é maior (Tabela 1$)$.

O uso de cinto de segurança está amplamente difundido (82,8\%). Não houve diferença na freqüência de AT entre os que usam cinto de segurança e os que não o usam ( $p=0,458)$.

A Tabela 2 apresenta as variáveis comportamentais que mostram diferenças significativas entre estudantes com antecedentes de acidentes e os sem esse evento. Os jovens com história de AT têm um perfil transgressor marcado. Todavia, mesmo entre os sem antecedentes de AT, há elevada freqüência de alguns comportamentos inadequados para o trânsito seguro (velocidade máxima, avançar sinal fechado e dirigir após beber).

Quanto à velocidade máxima, destaca-se que $9,9 \%$ dos condutores referiram atingir velocidade de $160 \mathrm{~km} / \mathrm{h}$ ou mais. Utilizando a pergunta sobre "sensações referidas ao dirigir em alta velocidade", observou-se que a freqüência de AT foi $12,3 \%$ para os que referem "não dirigir em alta velocidade", e no restante das categorias, $34,5 \%(\mathrm{p}<0,000)$. Os que valorizam dirigir em alta velocidade atribuem a este com- portamento significados como liberdade, independência, adrenalina; esta categoria não apresentou diferença estatisticamente significativa entre acidentados e não-acidentados. Já entre os que não valorizam dirigir em alta velocida$d e$, a subcategoria que refere "dirigir em alta velocidade por economia de tempo" teve $50 \%$ com antecedentes de AT $(\mathrm{p}<0,000)$.

Motoristas de ambos os sexos com história de AT apresentam opiniões e julgamentos que os diferenciaram significativamente dos motoristas sem envolvimento. Estas opiniões foram: ser "contrário à legislação de trânsito mais rigorosa" (41,6\% versus $12,1 \%)$ e acreditar que "motorista bom deve ser agressivo" (25,7\% versus $18,2 \%$ ).

Os motoristas "não-favoráveis a uma legislação de trânsito mais rígida”, apresentaram freqüência significativamente mais elevada de alguns comportamentos transgressores quando comparados aos motoristas "favoráveis à legislação mais rígida": velocidade média elevada $(37,8 \%$ versus $29,8 \% ; \mathrm{p}=0,030)$; velocidade máxima elevada $(61,7 \%$ versus $46,7 \%$; $\mathrm{p}<0,000)$; dirigir na contramão $(6,7 \%$ versus $3,1 \% ; \mathrm{p}=$ $0,008)$; dirigir pelo acostamento $(17,2 \%$ versus $11,9 \% ; \mathrm{p}=0,030)$; participar de rachas $(8,1 \%$ versus $4 \% ; \mathrm{p}=0,007)$; ter sido multado $(38,8 \%$ versus $26,3 \%$; $\mathrm{p}<0,000$ ) e dirigir logo após beber $(50 \%$ versus $37,2 \%$; $\mathrm{p}<0,000)$.

Houve maior proporção de acidentados entre os que atribuem os AT a "fatores externos ao motorista" (problemas de engenharia de trânsito, excesso de veículos, pedestres) do que entre os que atribuem os AT a "fatores dependentes do motorista" ( $43 \%$ versus $29,2 \%$; $\mathrm{p}=0,008$ ). Existem marcadas diferenças de gênero quanto 
Comportamentos no trânsito de condutores de ambos os sexos segundo antecedentes de acidente de trânsito ( $n=1.638$ )

Campinas, São Paulo, Brasil, 1996.

\begin{tabular}{|c|c|c|c|c|c|c|}
\hline Comportamentos & $\begin{array}{c}\text { Acidentados } \\
(\%)\end{array}$ & $\begin{array}{c}\text { Não-acidentados } \\
(\%)\end{array}$ & $x^{2}$ & $\mathbf{p}$ & OR bruto & IC $95 \%$ \\
\hline Dirigir após beber & 56,5 & 31,4 & 89,22 & 0,001 & 2,84 & $2,27-3,57$ \\
\hline Multas & 46,3 & 19,8 & 118,03 & 0,001 & 3,49 & $2,75-4,43$ \\
\hline Dirigir no acostamento & 20,9 & 8,6 & 46,12 & 0,001 & 2,80 & $2,04-3,85$ \\
\hline Suborno & 8,3 & 2,8 & 23,01 & 0,001 & 3,09 & $1,86-5,14$ \\
\hline Velocidade máxima $\geq 130 \mathrm{~km} / \mathrm{h}$ & 59,6 & 41,0 & 44,30 & 0,001 & 2,12 & $1,69-2,67$ \\
\hline Velocidade média $\geq 120 \mathrm{~km} / \mathrm{h}$ & 27,0 & 15,0 & 29,90 & 0,001 & 2,09 & $1,58-2,75$ \\
\hline Rachas & 7,3 & 3,4 & 11,48 & 0,001 & 2,23 & $1,35-3,68$ \\
\hline Ultrapassagem proibida & 29,7 & 19,9 & 22,54 & 0,001 & 1,81 & $1,40-2,33$ \\
\hline Avançar sinal fechado & 50,0 & 38,7 & 17,55 & 0,001 & 1,58 & $1,27-1,98$ \\
\hline Brigas no trânsito & 12,2 & 7,6 & 8,67 & 0,003 & 1,69 & $1,17-2,42$ \\
\hline
\end{tabular}

aos comportamentos inadequados para a segurança no trânsito. Os homens referiram maior proporção de transgressões, sendo a razão entre as proporções de 4,9 para rachas; 2,5 para dirigir após beber; 2,4 para suborno; 2,3 para velocidade de $130 \mathrm{~km} / \mathrm{h}$ ou superior; 2,1 para dirigir no acostamento; 1,9 para multas; 1,7 para ultrapassagens proibidas; 1,1 para avançar sinal fechado; somente a proporção de brigas (discussões) no trânsito foi maior entre as mulheres.

Entre os 491 estudantes com antecedentes de AT, $65,2 \%$ referiram um acidente, $20,8 \%$ referiram dois AT e $14 \%$, três ou mais. Entre os 369 condutores do sexo masculino com história de AT, observa-se que quanto maior a freqüência de AT, maior é o perfil transgressor, exceto no comportamento de avançar sinal fechado que não apresenta diferença estatisticamente significativa (Tabela 3 ).

Nos condutores de ambos os sexos as variáveis significativas na análise univariada foram: beber e dirigir, acesso a carro da família, antecedente de acidente como acompanhante, ser contrário à lei de trânsito mais rigorosa, motorista deve ser agressivo, ter emprego, multa, suborno, idade $\geq 20$, favorável à concessão de carteira aos 16 anos de idade, freqüência na direção (habitual), transporte para a universidade (próprio ou da família), renda econômica alta, gasto mensal elevado, idade de início na direção, ano de ingresso na universidade, tempo de direção. No sexo masculino, as variáveis que diferenciam os condutores com história de AT e os sem esse antecedente constam na Tabela 4 e são as que permaneceram significativas após o controle do confundimento, realizado pela análise de Regressão Logística. Além das variáveis comportamentais (multas, dirigir pelo acostamento e beber e dirigir) e de exposição ao trânsito (freqüência de direção habitual, AT como acompanhante e idade $\geq 20$ ) resultou incluída a variável sócio-econômica - renda elevada.

\section{Discussão}

Entre as limitações desta pesquisa destaca-se o $21 \%$ de não resposta (NR), sendo possível que parte deste fosse de infratores e acidentados. Assim, poderia estar sendo subestimada a associação entre comportamento infrator e acidente de trânsito.

As perguntas fechadas, exceto a renda dos pais, tiveram uma alta porcentagem de resposta $(99,6 \%-95,5 \%)$ e, assim, a confiabilidade das medidas de associação entre as variáveis independentes e o envolvimento em AT foi maior do que com as perguntas abertas. Houve diferença significativa na freqüência de NR para acidentados $(0,6 \%)$ e não-acidentados $(8,4 \%)$ em relação à renda dos pais e todas as variáveis de comportamentos no trânsito. A freqüência de NR foi maior entre os não-acidentados. Embora todas as variáveis comportamentais, exceto dirigir na contramão, tenham apresentado associação com AT, é possível que a maior porcentagem de NR entre os não-acidentados tenha diminuído a força da associação entre essas variáveis e AT.

A utilização de algumas perguntas abertas, apresentou como vantagem uma maior abrangência e, como desvantagens, a dificuldade de 
Condutores do sexo masculino com antecedentes de acidentes de trânsito, segundo o número de acidentes e tipo de comportamento de risco no trânsito $(n=369)$. Campinas, São Paulo, Brasil, 1996.

\begin{tabular}{|c|c|c|c|c|c|c|}
\hline \multirow[t]{2}{*}{ Comportamentos } & \multicolumn{2}{|c|}{$\begin{array}{c}\text { Número de acidentes } \\
\text { de trânsito }\end{array}$} & \multirow[t]{2}{*}{$x^{2}$} & \multirow[t]{2}{*}{ p } & \multirow[t]{2}{*}{ OR bruto } & \multirow[t]{2}{*}{ IC $95 \%$} \\
\hline & 3 ou mais (\%) & 1 e $2 \%$ & & & & \\
\hline Multas & 75,8 & 46,3 & 20,68 & 0,000 & 4,20 & $2,10-8,53$ \\
\hline Brigas no trânsito & 30,6 & 7,5 & 27,61 & 0,000 & 5,51 & $2,62-11,59$ \\
\hline Velocidade máxima $\geq 130 \mathrm{~km} / \mathrm{h}$ & 77,4 & 62,2 & 7,24 & 0,007 & 2,54 & $1,21-5,41$ \\
\hline Ultrapassagem proibida & 46,8 & 30,3 & 6,83 & 0,009 & 2,09 & $1,15-3,78$ \\
\hline Dirigir após beber & 75,8 & 62,9 & 6,04 & 0,014 & 2,29 & $1,12-4,78$ \\
\hline Suborno & 17,7 & 8,1 & 6,01 & 0,014 & 2,56 & $1,10-5,87$ \\
\hline Racha & 16,1 & 7,8 & 4,38 & 0,036 & 2,30 & $0,96-5,40$ \\
\hline Avançar sinal fechado & 58,0 & 47,9 & 2,38 & 0,122 & & \\
\hline
\end{tabular}

Tabela 4

Variáveis incluídas no modelo final de regressão logística e que diferenciam condutores do sexo masculino com e sem história de acidentes de trânsito $(n=1.010)$. Campinas, São Paulo, Brasil, 1996.

\begin{tabular}{lcccc}
\hline Variável & Estimativa & $\begin{array}{c}\text { Valor de } \mathbf{p} \\
\text { ajustado }\end{array}$ & $\begin{array}{c}\text { Odds Ratio } \\
\text { ajustado }\end{array}$ & IC 95\% \\
\hline Idade ( $\geq 20$ anos) & 0,7022 & 0,0004 & 2,018 & $1,364-2,986$ \\
$\begin{array}{l}\text { Acidentes de trânsito com } \\
\text { acompanhante }\end{array}$ & 0,8156 & 0,0001 & 2,261 & $1,671-3,059$ \\
Renda (elevada) & 0,5004 & 0,0016 & 1,649 & $1,2092,251$ \\
Freqüência na direção (habitual) & 0,5567 & 0,0013 & 1,745 & $1,243-2,449$ \\
Multa & 0,8084 & 0,0001 & 2,244 & $1,629-3,092$ \\
Dirigir no acostamento & 0,7340 & 0,0005 & 2,083 & $1,378-3,150$ \\
Dirigir após beber & 0,4079 & 0,0103 & 1,504 & $1,101-2,054$ \\
\hline
\end{tabular}

categorização e uma diminuição da possibilidade de observar associações devido à maior proporção de NR.

As perguntas sobre a velocidade média e a máxima em estrada tiveram porcentagem significativamente maior de NR entre os não-acidentados $(17,8 \%$ versus $4,1 \%$ e $19,2 \%$ versus $4,9 \%$, respectivamente). Isso pode ter diminuído a força de associação entre alta velocidade e AT e, assim, esta variável não integrou o modelo de regressão, diferentemente do estudo de French et al. (1993). Observa-se que, entre nós, há maior desrespeito ao limite de velocidade que no estudo de Wardle \& Steptoe (1991), em universitários de 18 a 30 anos no Reino Unido. As diferenças dão indícios para que a comunidade e as autoridades observem melhor a questão do respeito à legislação.
Chama a atenção que as mulheres briguem (discutam) mais que os homens; é provável que este achado guarde relação com o fato de serem universitárias, acostumadas a defender seus direitos e lutar para conquistar seu espaço no mundo masculino.

No sexo masculino, o modelo de regressão logística aponta, por um lado, a importância da maior exposição ao trânsito e, por outro, evidencia comportamentos inadequados para o trânsito seguro (dirigir logo após beber, multas anteriores e trafegar pelo acostamento). Deve considerar-se que "ter sido multado" é uma variável que compreende nela mesma as diversas transgressões às leis do trânsito. Esses resultados revelam a importância dos comportamentos de risco no envolvimento em acidentes. 
A presença da variável sócio-econômica "renda elevada" no modelo final representa uma exposição maior ao risco pela maior disponibilidade de uso de carro. A Associação Nacional de Transporte Público (ANTP, 1997), observa que quanto maior a renda, maior é a quantidade de $\mathrm{Km} /$ dia percorridos por veículos particulares. A renda elevada também pode favorecer a posse de veículos mais modernos e mais velozes estimulando a direção em alta velocidade. A associação entre nível sócio-econômico elevado e AT foi também evidenciada por Lima \& Ximenes (1998), em estudo de mortalidade.

No presente estudo, observa-se um perfil transgressor mais marcado entre condutores desfavoráveis a uma legislação de trânsito mais rígida, aproximando-se assim, dos dados de Parker et al. (1995), em que os condutores com elevado índice de transgressões mostram pouco interesse pelas normas. Ao julgar os acidentes em geral, os estudantes tenderam a responsabilizar mais o condutor, mas, ao avaliar as circunstâncias que os envolveram em AT, mencionaram circunstâncias alheias à sua responsabilidade. Esse perfil, associado à faixa etária jovem, também nos remete às teorias de adolescência (Knobel, 1984), que ao postular sobre a "Síndrome de Adolescência Normal", aponta, entre outras características, a oscilação de humor e o desejo de quebrar normas. Além desses aspectos, este autor destaca a influência da cultura.

Parker et al. (1995) identificam três tipos de comportamentos inadequados à direção. No presente estudo aparecem dois tipos, verbalizados em resposta à pergunta sobre os fatores que contribuíram para que se envolvessem em acidentes: os lapsos (distração, referida por $22,4 \%$ dos condutores) e as transgressões mencionadas como: imprudência $(5,3 \%)$, dirigir alcoolizado $(3,5 \%)$, dirigir em alta velocidade $(2,9 \%)$ e desrespeito à sinalização (1\%). Esses dados mostram que são poucos os que assumem ser responsáveis pela ocorrência de AT. Dados esses que também podem estar relacionados com características próprias da adolescência na sua acepção psicossocial e cultural, e que precisam ser melhor verificados em futuros estudos sobre adolescência e transgressão.

Como já descrito nos resultados, observase que os condutores que consideram que o bom motorista deve ser agressivo, apresentam um certo perfil de comportamentos de risco no trânsito (velocidade média e máxima elevadas, dirigem pelo acostamento, subornam e dirigem logo após beber) e se acidentam mais. Esses motoristas podem corresponder ao perfil descrito por Zuckerman (1998), como aqueles que "buscam sensações fortes". A análise das respostas é indicativa de uma possível associação entre agressividade e maior freqüência de transgressões no trânsito, também observada por Arnett et al. (1997).

Os dados apontam a necessidade de estudos voltados à influência da cultura e da função paterna na incorporação de normas (Vizzotto, 1995).

Com relação ao uso de álcool, o CDC (1993) observa sua presença em $15 \%$ dos acidentes sem lesão. Na presente pesquisa, menos de $4 \%$ reconhecem este hábito entre as circunstâncias que explicaram seu envolvimento em acidentes, mas os condutores de ambos os sexos que dirigem após beber apresentam risco 184\% maior de envolvimento em AT do que os sem esse comportamento (Tabela 2). No modelo final, restrito ao sexo masculino, o limite inferior do intervalo de confiança (IC) é pouco superior a um em decorrência do maior consumo de álcool neste sexo e menor diferença de consumo entre acidentados e não-acidentados. Esse hábito é muito mais freqüente entre nós do que no estudo de Wardle \& Steptoe (1991), no Reino Unido. A relativa baixa prevalência naquele país pode ser decorrente de medidas repressivas ou de hábitos e valores peculiares àquela cultura; todavia, entre nós este dado leva a uma preocupação social, indicando necessidade de estudos sobre medidas preventivas, procedimentos e técnicas interventivas nesta direção.

A nova legislação de trânsito inclui entre as infrações graves, dirigir sob o efeito do álcool. Além disso, mais recentemente surgiram propagandas antiálcool, veiculando repercussões sociais dos AT relacionados ao consumo de bebidas. O uso dessas estratégias de amedrontamento (reforço negativo) baseia-se na hipótese de que a censura social possa se contrapor à disponibilidade e, dessa forma, diminuir o hábito de dirigir após beber. Assim, prevê-se que esse hábito esteja diminuindo. Após a realização deste estudo, no Município de Campinas foi implantado um amplo sistema de controle eletrônico de velocidade e de semáforos que mediante a punição buscou a diminuição da prevalência do comportamento transgressor. Mesmo que, após esta pesquisa, diversas condições tenham melhorado, julgam-se necessárias intervenções educativas entre universitários, especialmente do sexo masculino, de classe sócio-econômica elevada e que consomem álcool. Especial atenção deve ser dada aos reincidentes de três ou mais AT pelo seu maior perfil transgressor.

Os valores e crenças sociais, além dos estereótipos em relação ao sexo masculino podem 
representar o poder e a fantasia de invulnerabilidade e conquista. Sugere-se ainda estudos que abranjam a assimilação da autoridade paterna, fundamental para a aprendizagem de normas, valores e leis.

Assim, especial atenção deve ser dada à família e pela família ao jovem, na busca de ações que apontem formas socialmente compatíveis e mais criativas de procurar "grandes sensações". O presente estudo sugere que as intervenções trabalhem com mudança de atitudes (crenças e valores instalados) bem como com modificação de comportamentos, paralelamente às medidas legais punitivas que, per se, não modificam comportamentos nem promovem mudanças atitudinais.

\section{Agradecimentos}

Ao Dr. Joel S. Giglio, por nos ter alertado sobre a importância social do tema. Às bolsistas Lídia Y. Komatsu e Simone, que participaram na aplicação dos questionários, e a Lídia e Carla pela digitação do banco de dados. À estatística Lusane Leão Baía, da Comissão de Pesquisa da Faculdade de Ciências Medicas - Unicamp, que realizou a análise de Regressão Logística. À Fundação de Amparo à Pesquisa do Estado de São Paulo, pelo apoio outorgado de acordo com o Processo № 96/00706-3.

\section{Referências}

ANDRADE, S. M. \& JORGE, M. H. P. M., 2000. Características das vítimas por acidentes de transporte terrestre em município da região sul do Brasil. Revista de Saúde Pública, 34:149-156.

ARNETT, J. J.; OFFER, D. \& FINE, M., 1997. Reckless driving in adolescence: "State" and "trait" factors. Accident Analysis \& Prevention, 29:57-63.

CDC (Centers for Disease Control and Prevention), 1993. Quarterly table reporting alcohol involvement in fatal motor-vehicle crashes. MMWR, 42:215.

FRENCH, D. J.; WEST, R. J.; ELANDER, J. \& WILDING, J. M., 1993. Decision-making style, driving style, and self-reported involvement in road traffic accidents. Ergonomics, 36:627-644.

KNOBEL, M., 1984. Síndrome da adolescência normal. In: Adolescência Normal (A. Aberastury \& M. Knobel, org.), pp. 24-62, Porto Alegre: Artes Médicas.
LIMA, M. L. C. \& XIMENES, R., 1998. Violência e morte: Diferenciais da mortalidade por causas externas no espaço urbano de Recife, 1991. $\mathrm{Ca}$ dernos de Saúde Pública, 14:829-840.

MARIN, L. \& QUEIROZ, M. S., 2000. A atualidade dos acidentes de trânsito na era da velocidade: Uma visão geral. Cadernos de Saúde Pública, 16:7-22.

MELLO-JORGE, M. H. P.; GAWRYSZEWSKI, V. P. \& LATORRE, M. R. D. O., 1997. Análise dos dados de mortalidade. Revista de Saúde Pública, 31(Sup. 4):5-25.

PARKER, D.; REASON, J. T.; MANSTEAD, A. S. R. \& STRADLING, S. G., 1995. Driving errors, driving violations and accident involvement. Ergonomics, 38:1036-1048.

PIRES, A. B.; VASCONCELLOS, E. A. \& SILVA, A. C., 1997. Transporte Humano: Cidades com Qualidade de Vida. São Paulo: Associação Nacional de Transportes Públicos. 
TAHA, I., 2001. Análise de acidentes de trânsito: Antes e após a implantação do novo CTB, em regiões do Estado de São Paulo. Revista ABRAMET, 37:8-25.

VIZZOTTO, M., 1995. O pai, a lei, a ordem e o aprendizado: Reflexões acerca do papel paterno no desenvolvimento infantil. In XVII International School of Psychology Colloquim, Anais, tomo II, pp. 389-390, Campinas: Pontifícia Universidade Católica de Campinas.

WARDLE, J. \& STEPTOE, A., 1991. The European Health and Behaviour Survey: Rationale, methods and initial results from the United Kingdom. Social Science and Medicine, 33:925-936.

WEST, R.; FRENCH, D.; KEMP, R. \& ELANDER, J., 1993. Direct observation of driving, self reports of driver behaviour, and accident involvement. Ergonomics, 36:557-567.

WHO (World Health Organization), 1976. The Epidemiology of Road Traffic Accidents. WHO Regional Publications European Series 2. Copenhagen: WHO Regional Office for Europe.
YUNES, J. \& RAJS, D., 1994. Tendência de la mortalidad por causas violentas en la población general y entre los adolescentes y jovens de la región de las Américas. Cadernos de Saúde Pública, 10(Sup. 1):88-125.

ZHANG, J.; FRASER, S.; LINDSAY, J.; CLARKE, K. \& MAO, Y., 2000. Padrões etários de fatores relacionados a acidentes de tráfego fatais: Enfoque sobre motoristas jovens e idosos. Revista ABRAMET, 35:42-47.

ZUCKERMAN, M., 1988. What lies beyond E and N? Factor analyses of scales believed to measure basic dimensions of personality. Journal of Personality and Social Psychology, 54:96-107.

Recebido em 7 de janeiro de 2002

Versão final reapresentada em 30 de setembro de 2002

Aprovado em 29 de novembro de 2002 